\title{
Dendritic Cells And Oral Transmission Of Prion Diseases
}

\author{
Fang-Ping Huang ${ }^{1,2}$ and G Gordon MacPherson ${ }^{1 \#}$
}

${ }^{1}$ Sir William Dunn School of Pathology, University of Oxford,

South Parks Road, Oxford OX1 3RE, UK

${ }^{2}$ Department of Pathology, University of Hong Kong,

Queen Mary Hospital, Pokfulam Road, Hong Kong, China

${ }^{\#}$ Author for correspondence: G Gordon MacPherson. 
Tel: +44 1865 275584; Fax +441865275501.

e-mail: gordon.macpherson@path.ox.ac.uk

\begin{abstract}
Transmissible spongiform encephalopathies (scrapie, BSE, Kuru) develop as CNS diseases after long incubation periods, and many of which may arise following the consumption of infected material. The infectious agent is thought to be a mis-folded form $\left(\mathrm{PrP}^{\mathrm{Sc}}\right)$ of a normal host protein $\left(\mathrm{PrP}^{\mathrm{C}}\right)$, which is relatively resistant to proteolytic degradation and which serves as a template, directing host PrP to accumulate in the misfolded form. Animal experiments have shown that CNS disease is preceded by a period in which the agent accumulates in secondary lymphoid organs (Peyer's patches, lymph nodes, spleen), particularly follicular dendritic cells in the B cell areas of these organs. How the agent is transmitted from the intestinal lumen to the FDCs is largely unknown. Dendritic cells (DCs, cells quite distinct from FDCs) are cells that are specialised to acquire antigens from peripheral tissues and to transport them to secondary lymphoid organs for presentation to $\mathrm{T}$ and $\mathrm{B}$ lymphocytes. We have shown that DCs can acquire $\operatorname{PrP}^{\mathrm{Sc}}$ from the intestinal lumen and deliver it to mesenteric lymph nodes. In this review we discuss the different stages involved in the migration of $\mathrm{PrP}^{\mathrm{Sc}}$ from the intestine to FDCs and consider the different stages and barriers involved in this process. We conclude that transport of the causative agent, using $\operatorname{PrP}^{\mathrm{Sc}}$ as a biomarker, from the intestine to FDCs is a very inefficient process, which may help to account for the apparent low frequency of individuals who have consumed infected material that go on to develop clinical disease.
\end{abstract}


Key words: Dendritic cells, Prion, TSE, Scrapie, Oral transmission, pathogenesis.

Key to abbreviations: CNS: central nervous system; DC: dendritic cell; FDC: follicular dendritic cell; GALT: gut-associated lymphoid tissues; LP: lamina propria; nvCJD: new variant Creutzfeldt-Jacob disease; PK: Protease K; PP: Peyer's patch; PrP: prion protein; $\operatorname{PrP}^{\mathrm{C}}$ : cellular isoform of $\operatorname{PrP}$; $\operatorname{PrP}^{\mathrm{Sc}}$ : scrapie associated PrP; TSE: transmissible spongiform encephalopathy; TSEA: TSE agent.

\section{Contents}

1. Introduction: Prions and the oral transmission of TSE

2. The immune system in prion diseases

3. Follicular dendritic cells as the site for prion propagation

4. Entry and transport of orally-acquired TSEA

5. Migrating intestinal dendritic cells transport $\mathrm{PrP}^{\mathrm{Sc}}$ from the gut

6. Natural barriers for oral prion entry?

7. Inflammation - 'danger' in another way?

8. Conclusions: Therapeutic and preventive prospects 


\section{Introduction: Prions and the oral transmission of TSE}

The oral route of infection has been implicated in the pathogenesis of transmissible spongiform encephalopathy (TSE), a disease that targets clinically the central nervous system (CNS). Spread of the disease, both naturally and experimentally, by ingestion of the infectious agent has been described in a variety of species ranging from domestic, as well as wild-life, animals to man [1-10]. The likelihood of spread of the bovine form of TSE (BSE) [11] to human (nvCJD) through the food-chain [6] has aroused long-lasting public health anxiety with adverse economical and political consequences, both in the UK and abroad for the last decade [12-14]. Due to the long incubation period of the illness, infected individuals may remain asymptomatic for years. It remains still highly uncertain as to how risky it has been, or how safe it is now, to eat beef or even meat from other animals likely to carry and pass on the mysterious 'mad cow' disease $[7,15]$. 
The disease has also led to the proposition of a novel mechanism of infectivity: that is an infectious agent (TSEA) possibly devoid of nucleic acid. This was first indicated by its refractoriness to UV irradiation [16]. It is also complicated by the many other unusual physical and biological properties of the molecules including, most worryingly, its extraordinary resistance to conventional sterilization procedures. The exact nature of the etiologic agent has been, and still is, a focus of scientific debate. Although the possible causal agent being an "unconventional slow virus" (Virino Theory) [17] is not excluded [18], live virus of this kind has not been isolated. The lack of specific immune response to the puzzling agent [19], and the absence of inflammatory cell infiltrate in the affected brains, seem to suggest otherwise [20, 21].

$\mathrm{PrP}^{\mathrm{Sc}}$, also known as 'scrapie-associated prion protein', is an abnormally folded, selfencoded protein $\left(\mathrm{PrP}^{\mathrm{C}}\right)$ that co-purifies with TSE infectivity $[22,23]$. The molecule is now considered to be the crucial, if not the only agent (Protein Theory), responsible for the infection [24]. Structurally, $\operatorname{PrP}^{\mathrm{Sc}}$ is rich in $\beta$-sheets, in contrast to the $\alpha$-helixrich $\operatorname{PrP}^{\mathrm{C}}$, and is insoluble in many detergents. The current hypothesis suggests that the pathogenesis involves a key step of prion protein conversion and replication in which $\mathrm{PrP}^{\mathrm{Sc}}$ converts the normal protein, $\operatorname{PrP}^{\mathrm{C}}$, into the abnormal form [25]. The agent replicates in this way by a post-translational alteration of the tertiary structure (conformational change), but not amino acid sequence, of the host-encoded protein, turning it into a highly self-aggregating, protease-resistant pathological isoform [26, 27]. The "Protein only" theory $[28,29]$ is supported by evidence from transgenic and knockout studies that mice devoid of $\operatorname{PrP}\left(\operatorname{Prnp}^{-/}\right)$are totally resistant to the disease 
[30], although it is not impossible that the protein is an intermediate yet indispensable molecule merely mediating neuropathology [18].

\section{The immune system in prion diseases}

A long incubation period preceding the neurological symptoms is common to all TSEs. Much evidence indicates that TSEA replication as described above is essential for the development of clinical disease and that such replication occurs, at least primarily, in the immune system.

In spite of the lack of any signs of an immune response, it has been known for a long that the immune system plays a crucial role in TSE pathogenesis [31]. Splenectomy of mice before infection significantly prolongs the incubation period of the disease after peripheral inoculation [32, 33], as does genetic asplenia [34], but athymia and neonatal thymectomy have no effect [33]. Severe combined immunodeficient (SCID) mice lacking mature $\mathrm{T}$ and $\mathrm{B}$ lymphocytes fail to develop the disease [32], but become susceptible after reconstitution with normal splenocytes [35]. Immunosuppressive drugs can prolong the incubation time of the disease [36], whereas stimulation of the lymphoid systems with mitogens enhances disease susceptibility [37].

Following peripheral infection, $\operatorname{PrP}^{\mathrm{Sc}}$ is detected in the spleen, lymph nodes and other lymphoid tissues long before CNS involvement [38-40]. The spleen however may not be the main organ involved in infection via the oral route, infectivity being found first in the Peyer's patches [39]. This suggests that the gut-associated lymphoid tissues 
(GALT) may serve a similar processing and replicative function for intestinallyrouted inocula. Early accumulation of $\operatorname{PrP}^{\mathrm{Sc}}$ in GALT, including mesenteric nodes, has also been described in sheep with scrapie, a natural TSE infection. At a later stage and to a lesser extent, the agent spreads to other systemic or non-gut-associated lymphoid tissues including the spleen [41-44]. Interestingly splenic $\operatorname{PrP}^{\mathrm{Sc}}$ accumulation is not detectable in cows naturally infected with BSE [45], but is evident in experimental animal models including BSE-infected mice[46] and sheep [47].

Thus peripheral lymphoid organs are important and perhaps indispensable in the transmission and development of the neurodegenerative disease. It is now believed that in most infectious forms of TSE, not only must the infectious agent transit through, but also replicate in the lymphoreticular compartment before invading the central nervous system [31]. Kaeser and colleagues showed recently that optimal prion replication requires $\mathrm{PrP}^{\mathrm{C}}$ expression by both stromal and haematopoietic compartments [48]. The questions then become: (1) what cell type(s) in the lymphoid organs that may support replication and propagation of prions; and (2) how exactly do these infectious proteins travel from their sites of penetration (e.g. gut) to sites of replication (lymphoid organs) thence into the CNS. A good understanding of these processes is obviously very important in early diagnosis as well as the development of new strategies for treatment and even prevention of the disease.

\section{Follicular dendritic cells as the site for prion propagation}


The cell type(s) likely to be involved in propagation of prions are thought to be of low density [49], long-lived and mitotically quiescent cells [50]. Follicular dendritic cells (FDCs) in the germinal centres of lymphoid organs or tissues display all these characteristics, and they are also strong PrP-expressing cells [51]. They have been long suspected to be the main cell type targeted by the TSE agents. In studies by many different groups, FDCs $[31,43,51-53]$ as well as some macrophages or macrophage-like cells $[41,43,54,55]$ are reported to be sites of $\mathrm{PrP}^{\mathrm{Sc}}$ accumulation soon after peripheral infection. It has been suggested that FDCs can capture prions through their complement receptors [56, 57], a similar cellular interaction described previously for the retention of HIV viruses by the cells [58]. The cell-free conversion of $\operatorname{PrP}^{\mathrm{C}}$ to $\operatorname{PrP}^{\mathrm{Sc}}$ in the presence of $\operatorname{PrP}^{\mathrm{Sc}}$ [59] suggests it is also possible that $\operatorname{PrP}$ may act as an autoligand.

Based on findings from several genetically modified mouse models, however, other groups of investigators argued that B cells [60], and possibly other unidentified cells [61], might be also crucial in peripheral prion transmission. The authors demonstrated that mice devoid of $\mathrm{B}$, but not $\mathrm{T}$, cells were resistant to disease inoculation via peripheral routes, while the animals remained equally sensitive to infection by intracerebral injection [62]. The same group reported subsequently that PrP expression in B lymphocytes was not required for prion neuroinvasion, since immunological constitution with haematopoietic precursors from PrP knock-out donors restored sensitivity to disease induction [60]. One explanation may be that B cells are not directly involved in replication but rather transport of the agents. Alternatively, the lack of B cells or B cell products may prevent FDC maturation and differentiation $[63,64]$. By using chimeric mouse models mismatched in PrP status 
between FDCs and other cells of the immune system, Brown and colleagues showed that replication of prions in the spleen depends on PrP-expressing FDCs rather than on lymphocytes or other bone marrow-derived cells, and that the contribution of B cells is related to their ability to induce the functional maturation of FDCs [65]. The role of FDCs in TSE pathogenesis, at least acting as the primary sites for prion replication, is once again emphasized and largely comfirmed.

\section{Entry and transport of orally-acquired TSEA}

An important question is how do FDCs acquire TSE agents following intestinal delivery, since FDCs are resident cells in B-cell follicles of organized lymphoid tissues (i.e. not peripheral tissues). TSE agents must first cross the intestinal epithelial barrier and be transported via lymphatics to the draining mesenteric nodes, or via the blood stream to the spleen (which lacks afferent lymphatic drainage). Transport of whole proteins or particles across intact epithelium is very inefficient. Thus it seems unlikely that passive transport across the epithelium and random distribution via the blood or lymph would suffice to deliver sufficient infective material to the lymphoid organs to initiate an infection.

Intestinal epithelium consists of a continuous sheet with individual cells joined by tight junctions. It forms an effective barrier to the movement of molecules and particles into the underlying connective tissues. The seal is however by no means complete, and it is possible that small amounts of macromolecules do transverse the epithelial barrier by transcytosis. In Peyer's patches and intestinal lymphoid follicles, the overlying epithelium is specialized to facilitate the transport of macromolecules 
and particles, and their delivery to lymphocytes and antigen presenting cells (APC) including DC. This transport is mediated by M cells, specialized epithelial cells that have poorly developed microvilli and that are able to rapidly transcytose tracers such as horse-radish peroxidase and fluorescent latex particles to the subjacent areas of the patch [66]. The ability of $\mathrm{M}$ cells to transport particles and macromolecules has been 'hi-jacked' by a number of intestinal pathogens to enable them to across the epithelia barrier [67-72].

\section{Migrating intestinal dendritic cells transport $\operatorname{PrP}^{\mathrm{Sc}}$ from the gut}

It is important not to confuse follicular DC with the 'conventional' DC also known as the 'Steinman' DC $[73,74]$. As compared in Table 1, the two types of cells share almost nothing except their 'dendritic' morphology. FDCs are long-lived cells that retain immune complexes on their surface for years and present them to B cells [75]. They are probably not haematopoietic. In contrast the 'Steinman' DC is a short-lived bone-marrow-derived cell found both in peripheral tissues and in the $\mathrm{T}$ cell areas of lymphoid organs. In peripheral tissues, they are actively endocytic [76] and in some circumstances are macropinocytotic, facilitating uptake of large amount of solutes and small particles [77]. The main function of these cells is to acquire antigens in peripheral tissues and transport them, via draining lymphatics, to secondary lymphoid organs [78]. DCs present processed antigen, as small peptides in association with MHC molecules, primarily to $\mathrm{T}$ cells, although they can also present intact antigens to B cells [79]. Some DCs are found to express the normal PrP protein [80, 81]. Importantly, unlike FDCs, DCs are actively migratory. 
Intestinal DCs are bone marrow-derived cells of the 'conventional' DC type, which migrate from the intestinal wall to draining mesenteric nodes. The area of PP underlying the dome is rich in DCs, macrophages and lymphocytes [82, 83]. DCs have also been described in the lamina propria (LP) [84]. Unlike tissue macrophages [85], DCs spend only a short time (2-4 days) in the intestinal wall, and migrate continuously to mesenteric lymph nodes via lymph. They have been shown to carry antigens acquired from the intestinal lumen [86], and apoptotic enterocytes [87]. These migrating cells are therefore in a unique position to transport prions from the gut. Andreoletti and colleagues have shown that in naturally infected sheep, $\operatorname{PrP}^{\mathrm{Sc}}$ deposits are found in association with a population of CD68-positive cells in the dome area and B follicles of PP before being detected in FDCs [43]. CD68 is a macrophage marker but it is also expressed at low level on some DCs $[88,89]$. By using thoracic duct cannulation of mesenteric lymphadenectomized rats, we have shown that intestinal $\mathrm{DC}$ but not $\mathrm{T}$ or $\mathrm{B}$ lymphocytes could indeed acquire $\mathrm{PrP}^{\mathrm{Sc}}$ from the intestinal lumen and transport them in lymph towards the mesenteric nodes within hours of oral infection (Fig.1) [90].

It is yet to be determined if DCs acquire $\operatorname{PrP}^{\mathrm{Sc}}$ after it has been internalised by $\mathrm{M}$ cells, or by direct uptake across the mucosal epithelium, as recently shown for the transport of apoptotic intestinal epithelial cells [87] and bacteria [91]. At least some DCs are known to leave PP and arrive in mesenteric nodes, and Szakal and Tew have previously shown a cell population in the cortex of lymph nodes which can transport immune complexes from the subcapsular sinus, where DCs are frequently found, to FDCs [92]. Whether and how DCs release prions for uptake by FDCs remains unknown, but DCs can release intact antigen in vivo for recognition by B cells . 
Release of cellular contents after cell death (DCs normally die within 3 days after reaching lymph nodes) is another possibility. It is of course also possible that oral TSE agents, once transported to ileal PP, probably via M cells, can reach and replicate on FDCs in situ, subsequently travelling to the CNS via enteric nerve endings $[54,93-$ 95]. However we have shown that they can also travel quickly to mesenteric nodes by hijacking intestinal DCs as a Trojan horse [90].

\section{Natural barriers for oral prion entry?}

In the experiment described above in which we could show $\operatorname{PrP}^{\mathrm{Sc}}$ in DCs after intestinal delivery, we were unable to show that they contained infective material [90]. This probably reflects the sensitivity of the assay given that only a small number of cells could be injected into each mouse used in the assay, and of those DCs injected, only a small proportion (usually $0.5-5 \%$ ) had acquired detectable amounts of $\mathrm{PrP}^{\mathrm{Sc}}$. A rough estimate suggests that only about one in ten thousand molecules given intestinally can be recovered from the DCs travelling in the thoracic duct lymph over a period of 16 hours. The efficiency of oral infection in animal models is generally very low in that ten times as much agent needs to be given orally compared to direct intra-cerebral inoculation [10]. Aucouturier and colleagues have demonstrated, using RAG knockout mice, that infected CD11c+ splenic dendritic cells (conventional DCs) alone, injected systemically (i.v.), are sufficient for prion propagation and transmission to the CNS [96]. The mice developed clinical disease without accumulation of prions in the spleen. This implies that CD11c+ dendritic cells can transport prions from the periphery to the CNS by a route not involving any additional lymphoid element. 
An alternative explanation for the low efficiency of oral infection is that there may exist strong natural barriers for the pathogen in the gut, including possibly the gastricintestinal enzymes, and the cellular enzymatic activities in DCs. -As shown in Figure 1 , the $\operatorname{PrP}^{\mathrm{Sc}}$ detected in the DC lysate appears to have been modified in some way and the characteristic three-band molecular signature after PK-treatment is not seen. This may be due, at least in part, to antigen processing in the DCs, since we have also demonstrated in vitro uptake of prion proteins by DCs leads to denaturation of the protein, followed by a time-dependent reduction in $\operatorname{PrP}^{\mathrm{Sc}}$ detectable by immunoblotting (Fig.2) [90, 97]. This might sound surprising, as $\mathrm{PrP}^{\mathrm{Sc}}$ is widely regarded as a protease-resistant molecule. The $\operatorname{PrP}^{\mathrm{Sc}}$ fingerprints that identify prion strains are judged by the resistance of $\operatorname{PrP}^{\mathrm{Sc}}$ to Protease $\mathrm{K}(\mathrm{PK})$, although its relative resistance to other proteases such as trypsin has also been demonstrated [98]. PK is however a fungal enzyme extracted from a mould (Tritirachium alnum). The enzymes in the cellular compartment and particularly gastro-intestinal tract are complex and identification of those responsible for $\mathrm{PrP}^{\mathrm{Sc}}$ degradation may be of therapeutic significance. It is also essential of course to determine whether the reduced immunoreactivity detected in DCs also correlates with diminished infectivity as previously reported for macrophages $[99,100]$.

These findings suggest that apart from the physical barrier formed by intestinal epithelium mentioned above, intracellular and possibly gastric-intestinal enzymes may be able to degrade prions - providing a natural barrier for prion entry that seems to have been largely overlooked previously. This barrier may explain the relative inefficiency often observed for oral/intragastric inoculation with TSE agents [10]. It 
may also explain why despite many people in the UK consuming infected beef only a very limited number of people have so far developed nvCJD and why a decline in nvCJD cases [101] rather than an epidemic as previously predicted [102, 103] appears to be the current trend. Nevertheless, whereas transmission of BSE to human (causing nvCJD), and of scrapie to laboratory animals, via the oral route seems to have been relatively inefficient, transmission of BSE to cattle appears to have occurred much more readily, as this was the mode of transmission that led to the epidemic of BSE. Furthermore, as mentioned above, splenic $\mathrm{PrP}^{\mathrm{Sc}}$ accumulation or replication does not appear to be necessary in the BSE-cattle transmission. An interesting and important question one may ask is therefore does this imply that cattle are somehow lacking in such degradative enzymes.

\section{Inflammation - "danger" in another way?}

The conclusion to be drawn from above findings is that the transmission of prion disease, especially via the oral route, may depend critically on a balance between clearance and propagation of the agent in the host. The normal intestinal immune system displays a balance in which pro-inflammatory and anti-inflammatory cells and molecules are carefully regulated to promote immunity against harmful invading pathogens while avoiding responses to self tissues and harmless dietary components [104]. The lack of inflammatory response in oral TSE infection may prevent the activation of macrophages whose phagocytic, enzymatic as well as phago-lysosomal fusion activities can be up-regulated by inflammation, speeding up the clearance process of the agent. It has been shown recently that the prion protein fragment 106126 is a chemoattractant for monocyte-derived immature but not mature DCs [105, 
106], and on which the receptor has also been identified [105]. This might mean that the initial migration of immature DCs towards $\operatorname{PrP}^{\mathrm{Sc}}$ can be regulated by the agent itself in the absence of overt inflammation. On the other hand the prion fragment can also enhance subsequent monocyte production of proinflammatory cytokines [105]. Inflammation stimulates the migration and maturation of DCs, which facilitates the transport of prion, and it is known that antigen processing is down-regulated in mature DC. The effects of inflammation may therefore alter the balance of prion uptake, retention and transport by DCs in several different ways, depending possibly on the stages of their transmission, DC maturation, and perhaps selectivity in the inflammatory mediators involved. It would make sense that the observed effects of immunosuppressive drugs on TSE susceptibility [36] could be due to their actions on the inflammatory machinery rather than the specific (B/T cells) immune system [107].

\section{Therapeutic and preventive prospects}

As described above recent evidence has indicated a role of DCs in delivering and possibly propagating prions following oral inoculation. One should remember however that the main function of DC is to initiate immune responses. Prion-infected animals can develop normal immune responses, both humoral and cellular, to conventional antigens or mitogens $[108,109]$ but the absence of immune reaction to $\operatorname{PrP}^{\mathrm{Sc}}$ is not surprising as it differs from the $\operatorname{PrP}^{\mathrm{C}}$ molecule only in tertiary structure. The fact that $\operatorname{PrP}^{\mathrm{C}}$ is a host-encoded protein and the immune system is presumably already tolerized to the molecule explains the lack of response. 
However it is quite possible that although T cells are tolerized, B cells are not. This is because the mode of antigen recognition by $\mathrm{T}$ and $\mathrm{B}$ cells is quite distinct. $\mathrm{T}$ cells can recognize only processed antigen as peptides in the context of MHC molecules. Since $\operatorname{PrP}^{\mathrm{Sc}}$ and $\operatorname{PrP}^{\mathrm{C}}$ share the primary structure (amino acid sequence, Diagram A), in theory, no $\mathrm{T}$ cell response would be expected, as reactive $\mathrm{T}$ cells would have been deleted in the thymus or tolerized in the periphery. However, the conformational changes of the protein may create new (foreign) epitopes (Diagram B) for B cells, which recognize native, unprocessed antigen. This implies that a B cell response may be potentially inducible providing that alternative $\mathrm{T}$ cell help can be offered. Encouraging findings have recently suggested a role for anti-prion molecules in disease prevention in a transgenic (mu chain anti-PrP) mouse model (Prnp knockout) [110]. This could provide an opportunity and rationale for novel therapeutic strategies in vaccine design by delivery of synthetic peptides with purpose-built $\mathrm{T}$ cell epitopes (Diagram C) attached to known B cell epitopes [111] leading to T-B, or DC-T-B (see below and Diagram D), collaborative responses. Efforts to identify such new B and T cell epitopes will rely on a good understanding of the 3-D structure not only for $\operatorname{PrP}^{\mathrm{C}}$ ${ }^{[112]}$ but, more importantly, for $\operatorname{PrP}^{\mathrm{Sc}}$, yet to be obtained.

Finally, DCs are a heterogeneous population of cells. DCs with immunogenic and tolerogenic properties have been shown in human and a variety of animal models $[113,114]$. In addition some DC subpopulations can retain intact antigen more efficiently than others. Identification and characterization of particular DC subsets that are responsible for transmitting the disease, that are mediating immunity against the causal agents, and their responses to inflammatory stimuli may also prove to be informative. Although the transport of prions by DC is an early event of the infection 
and hence is not likely to be a suitable site for intervention, potential therapeutic approaches may still be focused on how specific immunity to the agents can be effectively induced. These professional APC can be employed as a vector to deliver the 'modeled vaccine' mentioned above (Diagram D). In summary, a better understanding of all these aspects in prion pathogenesis could lead to rational immuno-manipulation strategies aimed at preventing the replication and spread of the infectious agents to the CNS. 


\section{References:}

1 J. K. Kirkwood, G. A. Wells, J. W. Wilesmith, A. A. Cunningham and S. I.

Jackson, Spongiform encephalopathy in an arabian oryx (Oryx leucoryx) and a greater kudu (Tragelaphus strepsiceros) [see comments], Vet Rec 127 (1990) 418-420.

2 J. M. Wyatt, G. R. Pearson, T. N. Smerdon, T. J. Gruffydd Jones, G. A. Wells and J. W. Wilesmith, Naturally occurring scrapie-like spongiform encephalopathy in five domestic cats [see comments], Vet Rec 129 (1991) 233-236.

3 I. H. Pattison, M. N. Hoare, J. N. Jebbett and W. A. Watson, Spread of scrapie to sheep and goats by oral dosing with foetal membranes from scrapie-affected sheep, Vet Rec 90 (1972) 465-468.

4 M. Alpers and D. C. Gajdusek, Changing patterns of kuru: epidemiological changes in the period of increasing contact of the Fore people with western civilization, Am J Trop Med Hyg 14 (1965) 852-879.

5 R. F. Marsh, R. A. Bessen, S. Lehmann and G. R. Hartsough, Epidemiological and experimental studies on a new incident of transmissible mink encephalopathy, J Gen Virol 72 (1991) 589-594. 

Alperovitch, et al., A new variant of Creutzfeldt-Jakob disease in the UK [see comments], Lancet 347 (1996) 921-925. encephalopathy to sheep and goats, Vet Rec 133 (1993) 339-341. Francis, et al., Infectivity in the ileum of cattle challenged orally with bovine spongiform encephalopathy, Vet Rec 135 (1994) 40-41.

9 R. H. Kimberlin and C. A. Walker, Pathogenesis of scrapie in mice after intragastric infection, Virus Res 12 (1989) 213-220.

10 S. B. Prusiner, S. P. Cochran and M. P. Alpers, Transmission of scrapie in hamsters, J Infect Dis 152 (1985) 971-978.

11 J. W. Wilesmith, G. A. Wells, M. P. Cranwell and J. B. Ryan, Bovine spongiform encephalopathy: epidemiological studies, Vet Rec 123 (1988) 638-644.

12 C. A. Donnelly, N. M. Ferguson, A. C. Ghani and R. M. Anderson, Implications of BSE infection screening data for the scale of the British BSE epidemic and current European infection levels, Proc R Soc Lond B Biol Sci 269 (2002) 2179-2190. 
13 W. Verbeke, Consumer reactions and economic consequences of the BSE crisis, Verh K Acad Geneeskd Belg 63 (2001) 483-492.

14 J. Watts, TOKYO Japan's government tries to allay BSE fears, Lancet 358 (2001) 2057.

15 S. C. MacDiarmid, Bovine spongiform encephalopathy (BSE) in sheep?, Aust Vet J 80 (2002) 148-149.

16 T. Alper, W. A. Cramp, D. A. Haig and M. C. Clarke, Does the agent of scrapie replicate without nucleic acid?, Nature 214 (1967) 764-766.

17 D. C. Gajdusek, Unconventional viruses and the origin and disappearance of kuru, Science 197 (1977) 943-960.

18 H. Narang, A critical review of the nature of the spongiform encephalopathy agent: protein theory versus virus theory, Exp Biol Med (Maywood) 227 (2002) 4-19.

19 D. D. Porter, H. G. Porter and N. A. Cox, Failure to demonstrate a humoral immune response to scrapie infection in mice, J Immunol 111 (1973) 14071410. 

Bendheim, et al., The nature of the unconventional slow infection agents remains a puzzle, Alzheimer Dis Assoc Disord 3 (1989) 79-99.

21 C. Weissmann, M. Enari, P. C. Klohn, D. Rossi and E. Flechsig, Transmission of prions, Proc Natl Acad Sci U S A 99 Suppl 4 (2002) 16378-16383.

22 C. F. Farquhar, R. A. Somerville and M. E. Bruce, Straining the prion hypothesis [letter; comment], Nature 391 (1998) 345-346.

23 S. B. Prusiner, D. C. Bolton, D. F. Groth, K. A. Bowman, S. P. Cochran and M. P. McKinley, Further purification and characterization of scrapie prions, Biochemistry 21 (1982) 6942-6950.

24 G. S. Jackson and A. R. Clarke, Mammalian prion proteins, Curr Opin Struct Biol 10 (2000) 69-74.

25 B. Oesch, D. Westaway, M. Walchli, M. P. McKinley, S. B. Kent, R. Aebersold, et al., A cellular gene encodes scrapie PrP 27-30 protein, Cell 40 (1985) 735-746.

26 S. B. Prusiner, Prions, Proc Natl Acad Sci U S A 95 (1998) 13363-13383.

27 S. B. Prusiner, M. R. Scott, S. J. DeArmond and F. E. Cohen, Prion protein biology, Cell 93 (1998) 337-348. 
28 J. S. Griffith, Self-replication and scrapie, Nature 215 (1967) 1043-1044.

29 S. B. Prusiner, Scrapie prions, Annu Rev Microbiol 43 (1989) 345-374.

30 H. Bueler, A. Aguzzi, A. Sailer, R. A. Greiner, P. Autenried, M. Aguet, et al., Mice devoid of PrP are resistant to scrapie, Cell 73 (1993) 1339-1347.

31 P. Aucouturier and C. Carnaud, The immune system and prion diseases: a relationship of complicity and blindness, J Leukoc Biol 72 (2002) 1075-1083.

32 H. Fraser and A. G. Dickinson, Pathogenesis of scrapie in the mouse: the role of the spleen, Nature 226 (1970) 462-463.

33 H. Fraser and A. G. Dickinson, Studies of the lymphoreticular system in the pathogenesis of scrapie: the role of spleen and thymus, J Comp Pathol 88 (1978) 563-573.

34 A. G. Dickinson and H. Fraser, Genetical control of the concentration of ME7 scrapie agent in mouse spleen, J Comp Pathol 79 (1969) 363-366.

35 C. I. Lasmezas, J. Y. Cesbron, J. P. Deslys, R. Demaimay, K. T. Adjou, R. Rioux, et al., Immune system-dependent and -independent replication of the scrapie agent, J Virol 70 (1996) 1292-1295. 

scrapie in mice after steroid administration, Nature 249 (1974) 855-856.

37 A. G. Dickinson, H. Fraser, I. McConnell and G. W. Outram, Mitogenic stimulation of the host enhances susceptibility to scrapie, Nature 272 (1978) $54-55$. infection in the mouse, J Infect Dis 117 (1967) 15-22.

39 R. H. Kimberlin and C. A. Walker, Pathogenesis of mouse scrapie: dynamics of agent replication in spleen, spinal cord and brain after infection by different routes, J Comp Pathol 89 (1979) 551-562.

40 D. A. Hilton, E. Fathers, P. Edwards, J. W. Ironside and J. Zajicek, Prion immunoreactivity in appendix before clinical onset of variant CreutzfeldtJakob disease [letter], Lancet 352 (1998) 703-704.

41 L. J. van Keulen, B. E. Schreuder, R. H. Meloen, G. Mooij-Harkes, M. E. Vromans and J. P. Langeveld, Immunohistochemical detection of prion protein in lymphoid tissues of sheep with natural scrapie, J Clin Microbiol 34 (1996) 1228-1231.

42 R. Heggebo, C. M. Press, G. Gunnes, K. I. Lie, M. A. Tranulis, M. Ulvund, et al., Distribution of prion protein in the ileal Peyer's patch of scrapie- free 
lambs and lambs naturally and experimentally exposed to the scrapie agent, $\mathrm{J}$ Gen Virol 81 (2000) 2327-2337.

43 O. Andreoletti, P. Berthon, D. Marc, P. Sarradin, J. Grosclaude, L. van Keulen, et al., Early accumulation of $\operatorname{PrP}(\mathrm{Sc})$ in gut-associated lymphoid and nervous tissues of susceptible sheep from a Romanov flock with natural scrapie, J Gen Virol 81 (2000) 3115-3126.

44 R. Heggebo, C. M. Press, G. Gunnes, L. Gonzalez and M. Jeffrey, Distribution and accumulation of PrP in gut-associated and peripheral lymphoid tissue of scrapie-affected Suffolk sheep, J Gen Virol 83 (2002) 479-489.

45 R. A. Somerville, C. R. Birkett, C. F. Farquhar, N. Hunter, W. Goldmann, J. Dornan, et al., Immunodetection of PrPSc in spleens of some scrapie-infected sheep but not BSE-infected cows, J Gen Virol 78 (1997) 2389-2396.

46 T. Maignien, C. I. Lasmezas, V. Beringue, D. Dormont and J. P. Deslys, Pathogenesis of the oral route of infection of mice with scrapie and bovine spongiform encephalopathy agents, J Gen Virol 80 (1999) 3035-3042.

47 J. D. Foster, D. W. Parnham, N. Hunter and M. Bruce, Distribution of the prion protein in sheep terminally affected with BSE following experimental oral transmission, J Gen Virol 82 (2001) 2319-2326. 

lymphoreticular prion propagation requires $\operatorname{PrP}(\mathrm{c})$ in stromal and hematopoietic cells, J Virol 75 (2001) 7097-7106.

49 M. C. Clarke and R. H. Kimberlin, Pathogenesis of mouse scrapie: distribution of agent in the pulp and stroma of infected spleens, Vet Microbiol 9 (1984) 215-225.

50 H. Fraser and C. F. Farquhar, Ionising radiation has no influence on scrapie incubation period in mice, Vet Microbiol 13 (1987) 211-223.

51 P. A. McBride, P. Eikelenboom, G. Kraal, H. Fraser and M. E. Bruce, PrP protein is associated with follicular dendritic cells of spleens and lymph nodes in uninfected and scrapie-infected mice, J Pathol 168 (1992) 413-418.

52 T. Kitamoto, T. Muramoto, S. Mohri, K. Doh Ura and J. Tateishi, Abnormal isoform of prion protein accumulates in follicular dendritic cells in mice with Creutzfeldt-Jakob disease, J Virol 65 (1991) 6292-6295.

53 A. F. Hill, R. J. Butterworth, S. Joiner, G. Jackson, M. N. Rossor, D. J. Thomas, et al., Investigation of variant Creutzfeldt-Jakob disease and other human prion diseases with tonsil biopsy samples, Lancet 353 (1999) 183-189. 
54 M. Beekes and P. A. McBride, Early accumulation of pathological PrP in the enteric nervous system and gut-associated lymphoid tissue of hamsters orally infected with scrapie, Neurosci Lett 278 (2000) 181-184.

55 M. Jeffrey, G. McGovern, C. M. Goodsir, K. L. Brown and M. E. Bruce, Sites of prion protein accumulation in scrapie-infected mouse spleen revealed by immuno-electron microscopy, J Pathol 191 (2000) 323-332.

56 N. A. Mabbott, M. E. Bruce, M. Botto, M. J. Walport and M. B. Pepys, Temporary depletion of complement component C3 or genetic deficiency of C1q significantly delays onset of scrapie, Nat Med 7 (2001) 485-487.

57 M. A. Klein, P. S. Kaeser, P. Schwarz, H. Weyd, I. Xenarios, R. M. Zinkernagel, et al., Complement facilitates early prion pathogenesis, Nat Med 7 (2001) 488-492.

58 P. Joling, L. J. Bakker, J. A. Van Strijp, T. Meerloo, L. de Graaf, M. E. Dekker, et al., Binding of human immunodeficiency virus type-1 to follicular dendritic cells in vitro is complement dependent, J Immunol 150 (1993) 10651073.

59 K. Kaneko, D. Peretz, K. M. Pan, T. C. Blochberger, H. Wille, R. Gabizon, et al., Prion protein (PrP) synthetic peptides induce cellular PrP to acquire properties of the scrapie isoform, Proc Natl Acad Sci U S A 92 (1995) 1116011164. 
60 M. A. Klein, R. Frigg, A. J. Raeber, E. Flechsig, I. Hegyi, R. M. Zinkernagel, et al., PrP expression in B lymphocytes is not required for prion neuroinvasion, Nat Med 4 (1998) 1429-1433.

61 L. Manuelidis, I. Zaitsev, P. Koni, Z. Y. Lu, R. A. Flavell and W. Fritch, Follicular dendritic cells and dissemination of Creutzfeldt-Jakob disease, $\mathbf{J}$ Virol 74 (2000) 8614-8622.

62 M. A. Klein, R. Frigg, E. Flechsig, A. J. Raeber, U. Kalinke, H. Bluethmann, et al., A crucial role for B cells in neuroinvasive scrapie [see comments], Nature 390 (1997) 687-690.

63 Z. F. Kapasi, G. F. Burton, L. D. Shultz, J. G. Tew and A. K. Szakal, Induction of functional follicular dendritic cell development in severe combined immunodeficiency mice. Influence of B and T cells, J Immunol 150 (1993) 2648-2658.

64 N. A. Mabbott, J. Young, I. McConnell and M. E. Bruce, Follicular dendritic cell dedifferentiation by treatment with an inhibitor of the lymphotoxin pathway dramatically reduces scrapie susceptibility, J Virol 77 (2003) 68456854. 
Fraser, et al., Scrapie replication in lymphoid tissues depends on prion proteinexpressing follicular dendritic cells, Nat Med 5 (1999) 1308-1312.

66 J. L. Wolf and W. A. Bye, The membranous epithelial (M) cell and the mucosal immune system, Annu Rev Med 35 (1984) 95-112.

67 J. L. Wolf, R. Dambrauskas, A. H. Sharpe and J. S. Trier, Adherence to and penetration of the intestinal epithelium by reovirus type 1 in neonatal mice, Gastroenterology 92 (1987) 82-91.

68 B. D. Jones, N. Ghori and S. Falkow, Salmonella typhimurium initiates murine infection by penetrating and destroying the specialized epithelial $\mathrm{M}$ cells of the Peyer's patches, J. Exp. Med. (1994) 15-23.

69 R. L. Owen, N. F. Pierce, R. T. Apple and W. C. Cray, Jr., M cell transport of Vibrio cholerae from the intestinal lumen into Peyer's patches: a mechanism for antigen sampling and for microbial transepithelial migration, J Infect Dis 153 (1986) 1108-1118.

70 R. I. Walker, E. A. Schmauder Chock, J. L. Parker and D. Burr, Selective association and transport of Campylobacter jejuni through $\mathrm{M}$ cells of rabbit Peyer's patches, Can J Microbiol 34 (1988) 1142-1147. 
71 L. R. Inman and J. R. Cantey, Peyer's patch lymphoid follicle epithelial adherence of a rabbit enteropathogenic Escherichia coli (strain RDEC-1). Role of plasmid-mediated pili in initial adherence, J Clin Invest 74 (1984) 90-95.

72 M. Regoli, C. Borghesi, E. Bertelli and C. Nicoletti, Uptake of a gram-positive bacterium (Streptococcus pneumoniae R36a) by the M cells of rabbit Peyer's patches, Anat Anz 177 (1995) 119-124.

73 R. M. Steinman, D. S. Lustig and Z. A. Cohn, Identification of a novel cell type in peripheral lymphoid organs of mice. III Functional properties in vivo, J. Exp. Med. 139 (1974) 1431-1435.

74 M. S. Sy and P. Gambetti, Prion replication-once again blaming the dendritic cell, Nat Med 5 (1999) 1235-1237.

75 G. J. Thorbecke, A. R. Amin and V. K. Tsiagbe, Biology of germinal centers in lymphoid tissue, Faseb Journal 8 (1994) 832-840.

76 C. Reis e Sousa, P. D. Stahl and J. M. Austyn, Phagocytosis of antigens by Langerhans cells in vitro, J Exp Med 178 (1993) 509-519.

77 F. Sallusto, M. Cella, C. Danieli and A. Lanzavecchia, Dendritic cells use macropinocytosis and the mannose receptor to concentrate macromolecules in the major histocompatibility complex class II compartment: downregulation 
by cytokines and bacterial products [see comments], J Exp Med 182 (1995) $389-400$.

78 R. M. Steinman, The dendritic cell system and its role in immunogenicity, Annu Rev Immunol 9 (1991) 271-296.

79 G. G. MacPherson, N. Kushnir and M. Wykes, Dendritic cells, B cells and the regulation of antibody synthesis, Immunol. Rev. 172 (1999) 325-334.

80 J. Burthem, B. Urban, A. Pain and D. J. Roberts, The normal cellular prion protein is strongly expressed by myeloid dendritic cells, Blood 98 (2001) $3733-3738$

81 M. Sugaya, K. Nakamura, T. Watanabe, A. Asahina, N. Yasaka, Y. Koyama, et al., Expression of cellular prion-related protein by murine Langerhans cells and keratinocytes, J Dermatol Sci 28 (2002) 126-134.

82 D. A. Hume, D. Halpin, H. Charlton and S. Gordon, The mononuclear phagocyte system of the mouse defined by immunohistochemical localisation of antigen F4/80 : Macrophages of endocrine organs., Proc Natl Acad Sci 81 (1984) 4171.

83 B. L. Kelsall and W. Strober, Distinct populations of dendritic cells are present in the subepithelial dome and $\mathrm{T}$ cell regions of the murine Peyer's patch, J Exp Med 183 (1996) 237-247. 
84 I. Maric, P. G. Holt, M. H. Perdue and J. Bienenstock, Class II MHC antigen (Ia)-bearing dendritic cells in the epithelium of the rat intestine, J Immunol 156 (1996) 1408-1414.

85 S. Gordon, S. Keshav and L. P. Chung, Mononuclear phagocytes: Tissue distribution and functional heterogeneity, Current Opinion in Immunology 1 (1988) 26-35.

86 L. M. Liu and G. G. MacPherson, Antigen acquisition by dendritic cells: intestinal dendritic cells acquire antigen administered orally and can prime naive T cells in vivo, J. Exp. Med. 177 (1993) 1299-1307.

87 F. P. Huang, N. Platt, M. Wykes, J. R. Major, T. J. Powell, C. D. Jenkins, et al., A discrete subpopulation of dendritic cells transports apoptotic intestinal epithelial cells to T cell areas of mesenteric lymph nodes, J. Exp. Med. 191 (2000) 435-444.

88 M. G. Betjes, M. C. Haks, C. W. Tuk and R. H. Beelen, Monoclonal antibody EBM11 (anti-CD68) discriminates between dendritic cells and macrophages after short-term culture, Immunobiology 183 (1991) 79-87.

89 H. Strobl, C. Scheinecker, E. Riedl, B. Csmarits, C. Bello-Fernandez, W. F. Pickl, et al., Identification of CD68+lin- peripheral blood cells with dendritic precursor characteristics, J Immunol 161 (1998) 740-748. 
MacPherson, Migrating intestinal dendritic cells transport $\operatorname{PrP}(\mathrm{Sc})$ from the gut, J Gen Virol 83 (2002) 267-271.

91 M. Rescigno, M. Urbano, B. Valzasina, M. Francolini, G. Rotta, R. Bonasio, et al., Dendritic cells express tight junction proteins and penetrate gut epithelial monolayers to sample bacteria, Nat Immunol 2 (2001) 361-367.

92 A. L. Szakal, K. L. Holmes and J. G. Tew, Transport of immune complexes from the subcapsular sinus to lymph node follicles on the surface of nonphagocytic cells, including cells with dendritic morphology., J Immuno 131 (1983) 1714.

93 P. A. McBride and M. Beekes, Pathological PrP is abundant in sympathetic and sensory ganglia of hamsters fed with scrapie, Neurosci Lett 265 (1999) $135-138$.

94 A. N. Shmakov, N. F. McLennan, P. McBride, C. F. Farquhar, J. Bode, K. A. Rennison, et al., Cellular prion protein is expressed in the human enteric nervous system, Nat Med 6 (2000) 840-841.

95 C. J. Sigurdson, T. R. Spraker, M. W. Miller, B. Oesch and E. A. Hoover, $\operatorname{PrP}(\mathrm{CWD})$ in the myenteric plexus, vagosympathetic trunk and endocrine glands of deer with chronic wasting disease, J Gen Virol 82 (2001) 2327-2334. 
96 P. Aucouturier, F. Geissmann, D. Damotte, G. P. Saborio, H. C. Meeker, R. Kascsak, et al., Infected splenic dendritic cells are sufficient for prion transmission to the CNS in mouse scrapie, J Clin Invest 108 (2001) 703-708.

97 K. M. Luhr, R. P. Wallin, H. G. Ljunggren, P. Low, A. Taraboulos and K. Kristensson, Processing and degradation of exogenous prion protein by CD11c(+) myeloid dendritic cells in vitro, J Virol 76 (2002) 12259-12264.

98 M. P. McKinley, D. C. Bolton and S. B. Prusiner, A protease-resistant protein is a structural componenet of the scrapie, Cell 35 (1983) 57-62.

99 R. I. Carp and S. M. Callahan, Effect of mouse peritoneal macrophages on scrapie infectivity during extended in vitro incubation, Intervirology 17 (1982) 201-207.

100 V. Beringue, M. Demoy, C. I. Lasmezas, B. Gouritin, C. Weingarten, J. P. Deslys, et al., Role of spleen macrophages in the clearance of scrapie agent early in pathogenesis, J Pathol 190 (2000) 495-502.

101 A. C. Ghani, C. A. Donnelly, N. M. Ferguson and R. M. Anderson, Updated projections of future vCJD deaths in the UK, BMC Infect Dis 3 (2003) 4.

102 S. N. Cousens, E. Vynnycky, M. Zeidler, R. G. Will and P. G. Smith, Predicting the CJD epidemic in humans, Nature 385 (1997) 197-198. 
103 P. G. Smith, The epidemics of bovine spongiform encephalopathy and variant Creutzfeldt-Jakob disease: current status and future prospects, Bull World Health Organ 81 (2003) 123-130.

104 R. P. MacDermott, Alterations of the mucosal immune system in inflammatory bowel disease, J Gastroenterol 31 (1996) 907-916.

105 Y. Le, H. Yazawa, W. Gong, Z. Yu, V. J. Ferrans, P. M. Murphy, et al., The neurotoxic prion peptide fragment $\operatorname{Pr} \mathrm{P}(106-126)$ is a chemotactic agonist for the G protein-coupled receptor formyl peptide receptor-like 1, J Immunol 166 (2001) 1448-1451.

106 N. C. Kaneider, A. Kaser, S. Dunzendorfer, H. Tilg and C. J. Wiedermann, Sphingosine kinase-dependent migration of immature dendritic cells in response to neurotoxic prion protein fragment, J Virol 77 (2003) 5535-5539.

107 G. W. Outram, A. G. Dickinson and H. Fraser, Slow encephalopathies, inflammatory responses and arachis oil, Lancet 1 (1975) 198-200.

108 A. C. Gardiner and A. A. Marucci, Immunological responsiveness of scrapie infected mice, J Comp Pathol 79 (1969) 233-235. 
109 D. T. Kingsbury, D. A. Smeltzer, C. J. Gibbs, Jr. and D. C. Gajdusek, Evidence for normal cell-mediated immunity in scrapie-infected mice, Infect Immun 32 (1981) 1176-1180.

110 F. L. Heppner, C. Musahl, I. Arrighi, M. A. Klein, T. Rulicke, B. Oesch, et al., Prevention of scrapie pathogenesis by transgenic expression of anti- prion protein antibodies, Science 294 (2001) 178-182.

111 L. E. Soto Ramirez, B. Renjifo, M. F. McLane, R. Marlink, O. H. C, R. Sutthent, et al., HIV-1 Langerhans' cell tropism associated with heterosexual transmission of HIV, Science 271 (1996) 1291-1293.

112 K. J. Knaus, M. Morillas, W. Swietnicki, M. Malone, W. K. Surewicz and V. C. Yee, Crystal structure of the human prion protein reveals a mechanism for oligomerization, Nat Struct Biol 8 (2001) 770-774.

113 R. M. Steinman, D. Hawiger and M. C. Nussenzweig, Tolerogenic dendritic cells, Annu Rev Immunol 21 (2003) 685-711.

114 F. P. Huang and G. G. MacPherson, Continuing Education of the Immune System - Dendritic Cells, Immune Regulation and Tolerance, Current Molecular Medicine 1 (2001) 457-468. 
Table 1: Dendritic cells and follicular dendritic cells are distinctive cell types

Cell: $\quad$ Follicular dendritic cell

Ontogeny: Obscure, non-haemopoietic

Distribution: Secondary lymphoid organs

(B cell follicles)

Life-span: Long (years)

Functions: Antigen presentation (B cells as immune complexes)

Migration: Non-migratory, resident

\section{Dendritic cell}

Bone marrow-derived, haemopoietic

Peripheral tissues, secondary

lymphoid organs ( $\mathrm{T}$ cell areas)

Short (days - not Langerhans cells)

Antigen presentation (peptides to $\mathrm{T}$

cells on MHC)

Actively migratory 


\section{Figure Legends}

Figure 1. Intestinal DCs transport PrPSc to mesenteric nodes via lymph. Lymph was collected 8 to $16 \mathrm{~h}$ after intestinal injection of mouse scrapie-associated fibrils (ME7 SAF). Conspicuous PrP+ cytoplasmic inclusions were detected by immunocytochemistry in a small proportion of DCs (a) but not B (b) or T (c) lymphocytes in the thoracic duct lymph of mesenteric lymphadenectomized rats. (d) Control DCs from PBS-injected animals. Magnification x1000.

(e) Immunoblot analysis of pooled cell lysates (1x106 cells per lane) from SAFtreated rats confirmed the presence of PrPSc in lymph DCs (lane 4) but not in T or B lymphocytes. SAF equivalent to 2 or $4 \mu \mathrm{g}$ of infected brain tissue was loaded in lanes 5 and 6, respectively. Treatment of samples in the presence (+) or absence (-) of proteinase $\mathrm{K}(\mathrm{PK})$ before electrophoresis is indicated. In all panels, PrP was detected using the PrP-specific polyclonal antiserum 1B3.

(Huang et al. JGV 2002; 83:267-271)

Figure 2. DCs acquire and process PrPSc following in vitro culture with SAF. Bone marrow-derived DCs (BMDC, 1x106 cells) were cultured in the absence (BMDC alone) or presence of SAF (equivalent to $10 \mathrm{mg}$ infected brain tissue) for the times indicated. Immunoblots show the accumulation of detergent-insoluble, relatively proteinase K-resistant PrPSc within BMDC lysates. Treatment of lysates in the presence $(+)$ or absence $(-)$ of proteinase $\mathrm{K}(\mathrm{Pk})$ is indicated. SAF was incubated in medium alone as a control. Following Pk treatment, a typical three-band pattern was observed between molecular mass values of 20 and $30 \mathrm{kDa}$, representing unglycosylated, monoglycosylated and diglycosylated isomers of $\operatorname{PrP}$ (in order of 
increasing molecular mass). SAF equivalent to $50 \mu \mathrm{g}$ infected brain tissue and/or BMDCs equivalent to 104 cells were loaded per lane.

(Huang et al. JGV 2002; 83:267-271)

Figure 3: Modeling $T$ cell epitopes for inducing DC-T-B cell collaborative responses against PrPsc. Schematic representations of the primary sequence (A) and tertiary structure (B) of PrPsc, and the purpose-built synthetic new epitope for T cell recognition $(\mathrm{C})$. Cellular interactions, antigen presentation and recognition by DC, B and $\mathrm{T}$ cells after encountering the natural $\mathrm{B}$ cell epitope $(\mathrm{b} \mathrm{d} \mathrm{f})$ and the synthetic $\mathrm{T}$ (and B) cell epitope (b'd'f') are depicted in (D). 


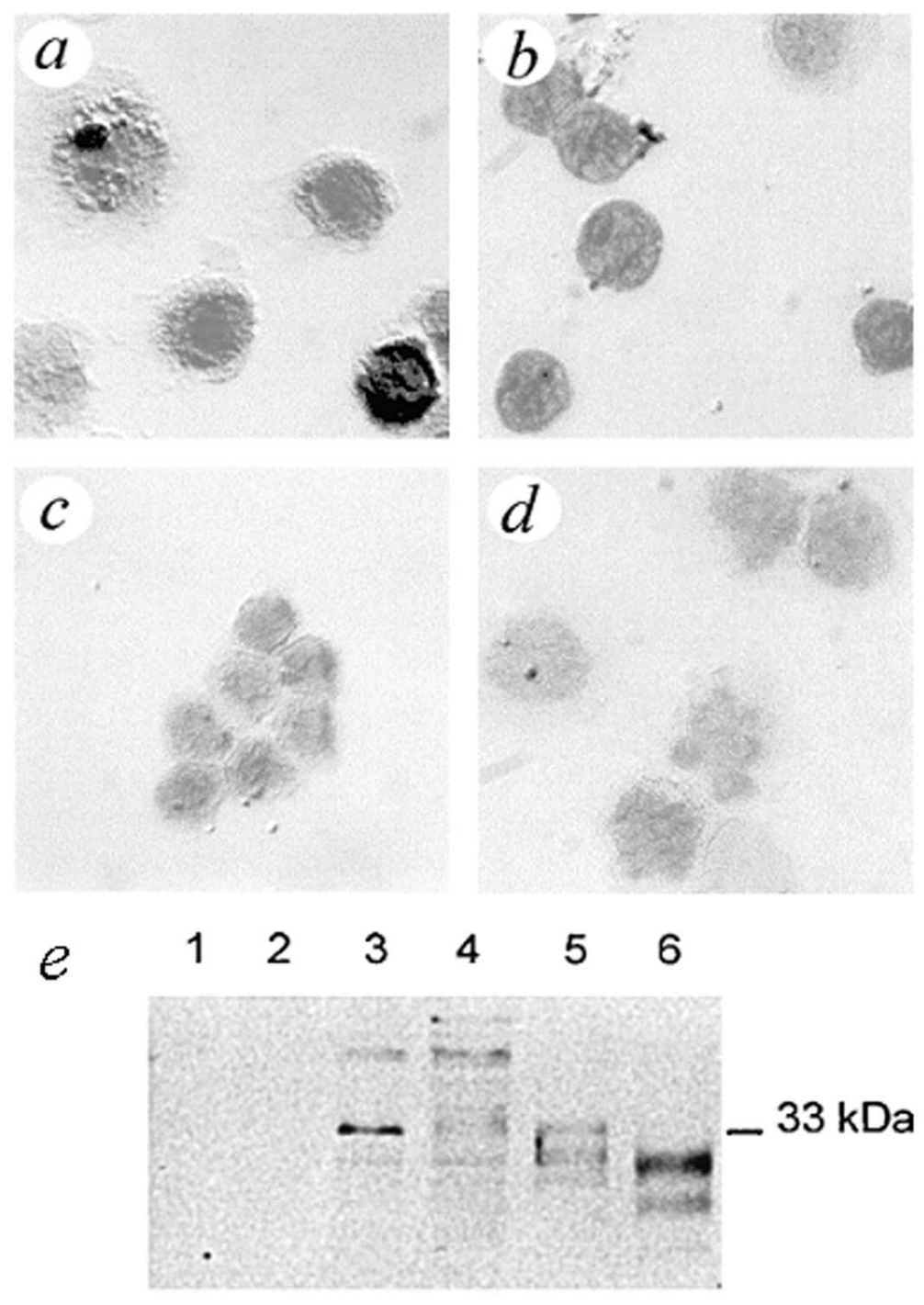

Cells $T$ B DC DC SAF SAF

PK - - - + $+\quad+$ 
(A) $\ldots a b c d e f g \ldots$

(B)

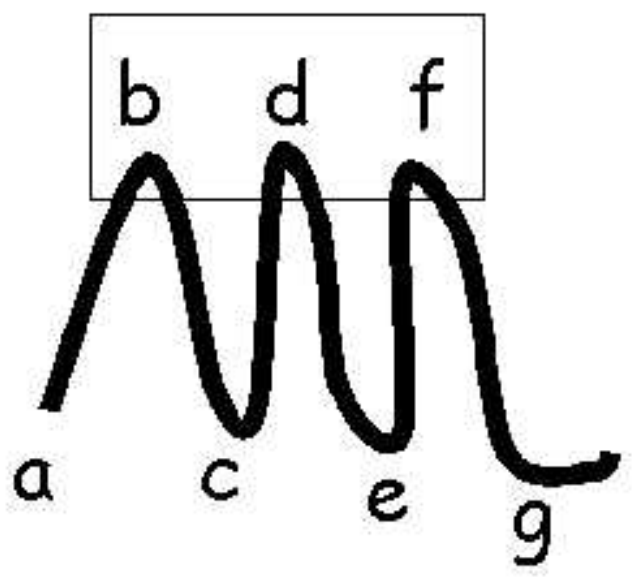

(C)

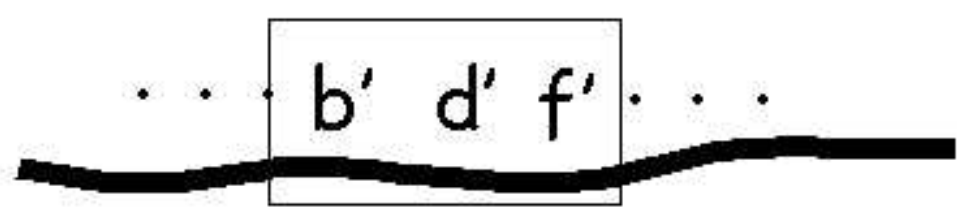

(D)

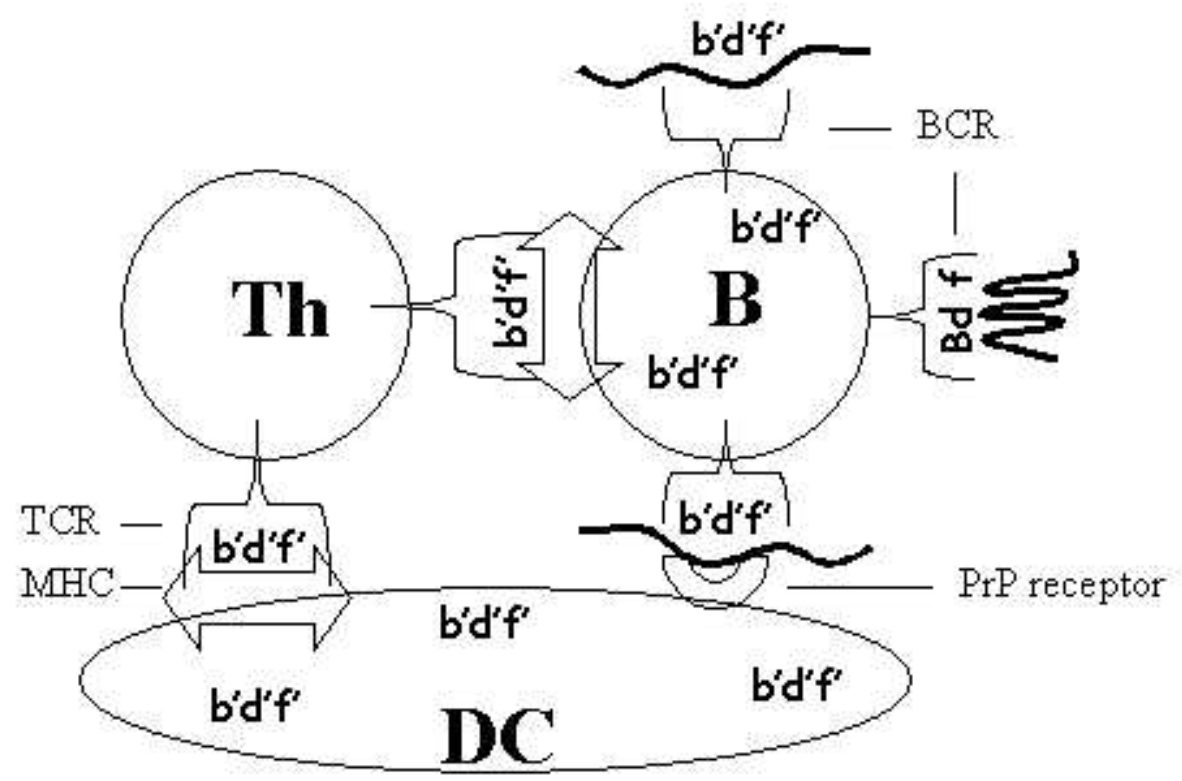




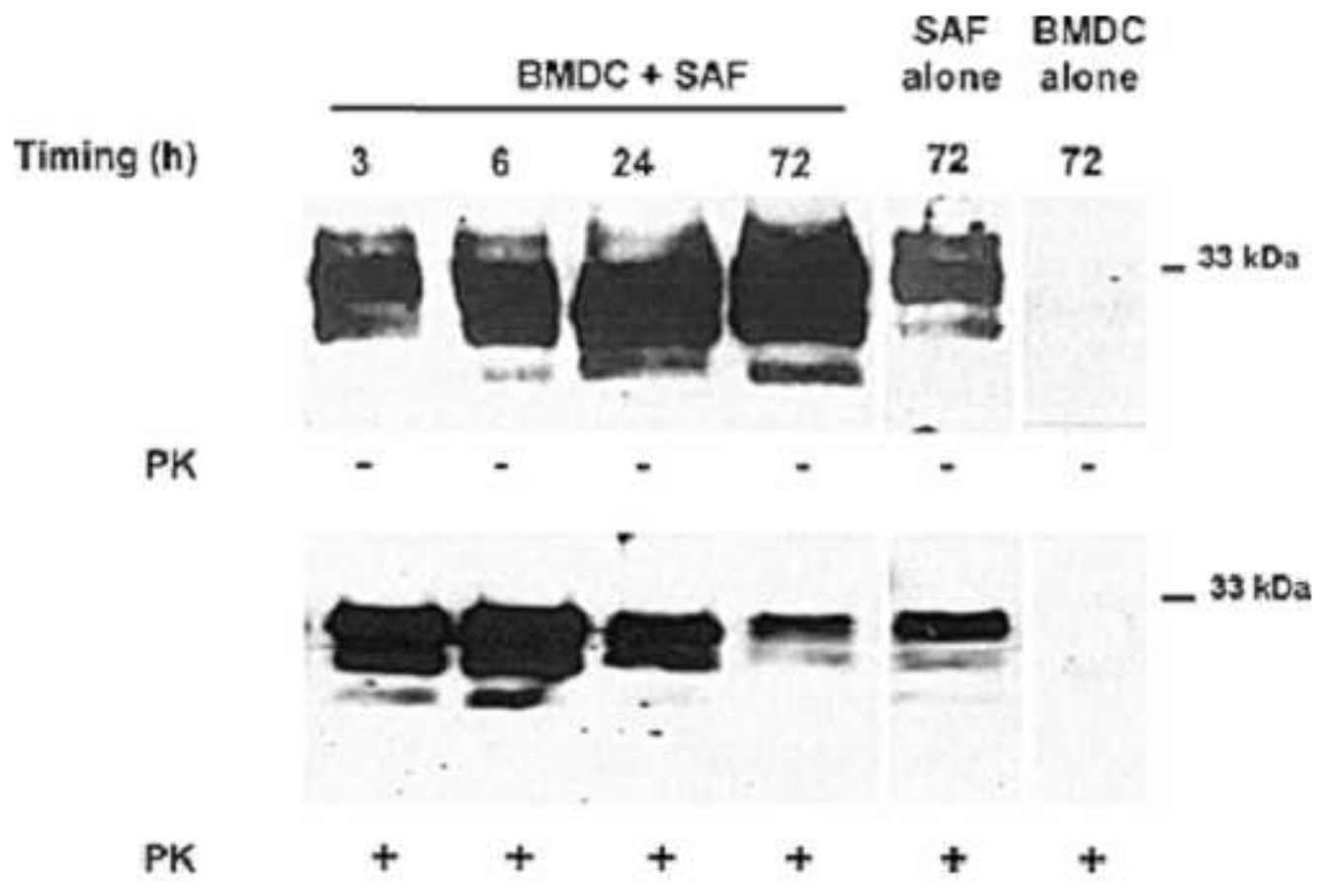

